considered in this case after the disease being treated which is consistent with the hypothesis.

\section{PO-0854 THE BIG PICTURE: CASE REPORT OF AN INTRACRANIAL DISSECTING ANEURYSM}

AC Prelhaz, I Marques, I Bretes, C Didelet, S Rocha. Pediatrics, Centro Hospitalar BarreiroMontijo, Lisboa, Portugal

\subsection{6/archdischild-2014-307384.1480}

Background Aneurysms affecting the posterior inferior cerebellar artery-vertebral artery complex (PICA-VA) represent 0,5-3\% of all intracranial aneurysms and, in children, they are rarely recognised.

Most children present with eye symptoms, ataxia, headache, vomiting, limb paresis/paralysis and/or impaired consciousness. Neck pain, one of the hallmark symptoms in adults, is often absent.

Case report The authors present a 22 months infant, admitted at the Emergency Room after an episode of labial cyanosis and cutaneous pallor followed by prostration and altered gait pattern; without seizure or loss of consciousness. He presented hemodynamically stable, with right peripheral facial palsy, ipsilateral truncal imbalance and head rotation and refusal to walk. No evidence of oculoparesis, motor deficits or meningeal signs.

Brain CT-scan showed vascular dilation in the posterior cranial fossa, compressing medulla oblongata and pons structures. Angio-MR confirmed the presence of dissecting aneurysms of the right PICA and 4th segment of the right VA, with intramural thrombus and compression of the brainstem, without ischemia or bleeding.

A stent was placed in the PICA and an intravascular embolization coil in the VA. The child was discharged with no evidence of new neurological deficits.

An history of repeated minor head trauma in the context of tantrums was posteriorly clarified.

Conclusion In this case, as in literature, association between symptomatic PICA-VA aneurysms and minor head or cervical trauma seems possible. Often, there is no other underlying abnormality.

Despite the frightening presentation, prognosis is usually good. An endovascular approach seems to be safe and efficient in treating this condition.

\section{PO-0855 DEVELOPMENTAL CONSULTANCY AT ZEMUN'S HEALTH CENTRE: RISK FACTORS IN NEONATES (1991-2010) WITH EMPHASIS ON ASPHYXIA, INTRACRANIAL HAEMORRHAGE AND HYPOXIC-ISCHAEMIC ENCEPHALOPATHY}

${ }^{1}$ D Radivojevic, ${ }^{2} \mathrm{~T}$ Medic, ${ }^{3} \mathrm{~V}$ Medic. ${ }^{1}$ Department of Paediatrics, Zemun's Health Center, Belgrade, Serbia; ${ }^{2}$ Clinic for Physical Medicine and Rehabilitation, Clinical Center of Serbia, Belgrade, Serbia; ${ }^{3}$ Department of Kinesiology Prosthetics and Orthotics, High Sanitary Medical School of Applied Sciences "VISAN", Belgrade, Serbia

10.1136/archdischild-2014-307384.1481

Background and aims To present at-risk factors in neonates (,at-risk“ babies) to the total number of children born in Zemun (the large municipality in Belgrade) between 1991 and 2010; to sort risk factors with emphasis on asphyxia, intracranial haemorrhage (ICH) and hypoxic-ischaemic encephalopathy (HIE), as

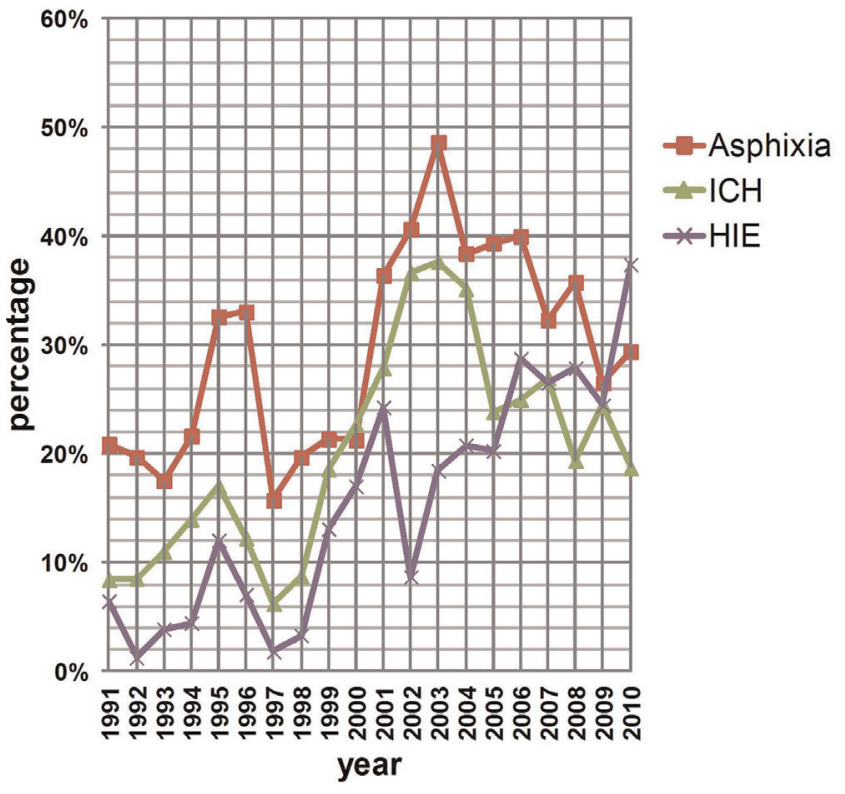

Abstract PO-0855 Figure 1 The number of "at-risk" babies and risk factors to the number of babies

the most serious factors that could be responsible for brain damage and a number of disorders.

Method The study population of neonates observed and registered in the Zemun`s Health Centre“.

Results During the twenty-year period (1991-2010) 20.716 babies were born (minimum 772 in 1993, maximum 1241 in 2009), among them 3.506 (16,94\%) were „at-risk“ babies. In the period 1997-1998 it was evident increase in „at-risk“ babies, when the maximum was $34,73 \%$ in 1998 , compared to the minimum of $12,00 \%$ in 2003 (Figure 1). A new increasing trend of "at-risk" babies in the period 2003-2010 was noticed. Absolute and the relative change of the most serious risk factors are shown in Figure1 and Figure 2, respectively. Very often asphyxia was dominant over all risk factors (1995-1996, 2001-2006). ICH increased till 2002, both absolutely and relatively, after he

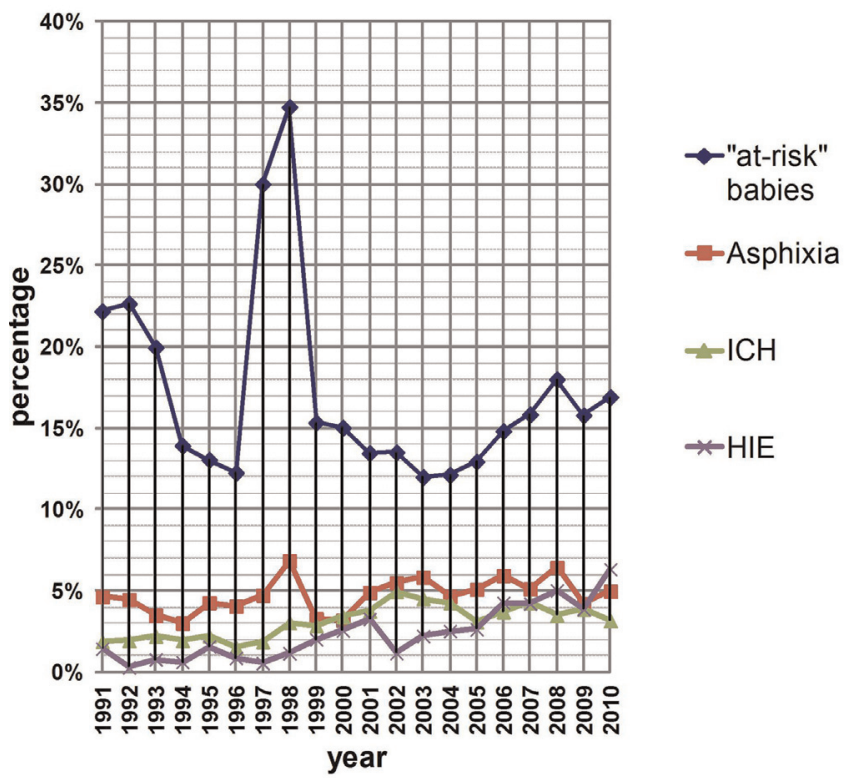

Abstract P0-0855 Figure 2 The number of risk factors to the number of "at-risk" babies 
decreased. HIE has an increasing trend over the whole period. Concerning the period 1991-2010, 141 ,at-risk“ babies stay with handicap $(4,02 \%$ in risk population, $0,68 \%$ in total population).

Conclusion Within the period 1991-2010, a new trend of increasing „at-risk“ babies and HIE (2003-2010) requires attention, while in the same period asphyxia and ICH had a declining trend. In our Developmental consultancy all of "at-risk" children are constantly observed and treated in their best interest.

\section{P0-0856 KETOGENIC DIET AND TUBEROUS SCLEROSIS: A ROMANCE?}

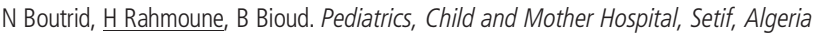

\subsection{6/archdischild-2014-307384.1482}

Introduction Brain injuries of tuberous sclerosis have a particularly severe clinical appearance because they are providers of heavy effects and can be life-threatening

We present a special scheme that was believed, wrongly, archaic effect.

Material and methods A young infant is followed since the age of 9 months for TS with refractory epilepsy and autism, without parenchymal CNS tumour.

After many therapies, a ketogenic diet is proposed... The suites are fantastic: 1 single seizure after one year of follow-up (4 years old) and decreased aggressiveness of the patient

Result and discussion Tuberous sclerosis (TS) is a phacomatosis due to mutations in tumour suppressor genes (TSC1 and TSC2).

Epilepsy can be the first clinical sign and occur at any age : 60-90\% of TS patients have epilepsy. The earliest type and the most characteristic is the West syndrome.

Current research indicates that mTOR integrates information from multiple signalling pathways, including insulin, growth factors (such as IGF-1 and IGF- 2) and mitogens. mTOR is also an indicator of the amount of available nutrients for the cell, as well as the energy and redox status.

Thus, the continuous decrease of nutrient inputs inhibits sensible cell receptor of the mTOR pathway and induces a suppressive response with an inverse pathophysiological mechanism.

Conclusion Although "ancient", the ketogenic diet has been "updated", especially in support of the TS; thanks to genetic advances, noting the crucial role of nutritional receptors by inactivating the mTOR pathway.

\section{PO-0857 CENTRAL NERVOUS THROMBOPHLEBITIS AND BEHÇET DISEASE}

${ }^{1} \mathrm{~N}$ Boutrid, ${ }^{1} \mathrm{H}$ Rahmoune, ${ }^{2} \mathrm{FC}$ Rahmoune, ${ }^{1} \mathrm{~A}$ Loucif, ${ }^{1} \mathrm{~B}$ Bioud. ${ }^{1}$ Pediatrics, University Child and Mother Hospital, Setif, Algeria; ${ }^{2}$ Anesthesiology, AP-HP Bicêtre Hospital, Paris, France

\subsection{6/archdischild-2014-307384.1483}

Introduction Behcet's Disease (BD) is manifested by a triad of relapsing hypopyon uveitis, aphthous stomatitis and genital ulcers.

We present the case of a school-aged boy with a Behçetrelated acute cerebral venous thrombosis.

Material and method A 8 years old boy is admitted for acute and severe headaches with nausea.

Clinical examination notes a febrile child with marked aphtous mouth (with a history of genital 'burns').
ESR and CRP are mildly high, while cerebral angio-CT reveals a superior sagittal sinus occlusion.

Steroids and palliative management completely resolve these symptoms, while angio-MRI confirms the isolated thrombophlebitis.

Discussion The major manifestations of vascular Behcet Disease include venous occlusion, arterial occlusion and aneurysm formation.

Cerebral venous thrombosis (CVT) results in signs and symptoms of increased intracranial pressure, like for our child.

Steroids remain the mainstay initial treatment, with a particular attention to anticoagulation and adjunction/relay with colchicine.

Conclusion Cerebral venous thrombosis may reveal BD is associated with a good prognosis when treated promptly, specially in paediatric patients.

\section{P0-0858 WITHDRAWN}

\section{P0-0859 DIAGNOSTIC ASSESSMENT AND HEALTH SURVEILLANCE IN CEREBRAL PALSY}

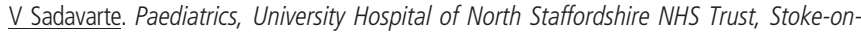
Trent, UK

\subsection{6/archdischild-2014-307384.1484}

Background and aims Cerebralpalsy is an umbrella term for a group of disorders affecting body movement, balance and posture. Attempt should be made to establish the underlying cause. Children should be monitored for comorbidities, so that early intervention could be undertaken.

Method Retrospectivestudy of case notes of all children known to have cerebral palsy in Telford and Wrekin in UK.

Results There were 36 children, aged 2 yrs 9 mths to 15 yrs 8 mths (at Sep 09) - 24 boys and 12 girls.

Most children (91\%) were given the diagnosis belowthe age of 24 mths (mean 16.3 mths).

11 (31\%) were preterm, under 32 weeks gestation and 18 $(50 \%)$ were born at term.

$11(31 \%)$ are in special schools.

$32(89 \%)$ were investigate dradiologically. There were radiological abnormalities in $69 \%$ of those scanned.

The majority of children, 32 (89\%) had SpasticCP of which$14(42 \%)$ had diplegia.

22 out of 36 children (61\%) had co morbid problems.

Screening for co morbidities was noted to beinconsistent.

Conclusions Neuroimagingis recommended in the evaluation of cerebral palsy if the aetiology is notestablished. ${ }^{1}$ Other investigations such as metabolic and genetic studies should be guided by the clinical presentation. A unified pathway with a checklist highlighting key points to identify co morbidities early is suggested to improve the quality of care.

\section{REFERENCE}

1 Ashwal S et al 2004 Practice Parameter :Diagnostic assessment of children withcerebral Palsy. Neurology 2004:62:851-863e. Attempt should be made to establish underlying cause

\section{PO-0860 PAEDIATRIC STROKE: A LITERATURE REVIEW}

M Sammut. Paediatrics, Mater Dei Hospital, Msida, Malta

10.1136/archdischild-2014-307384.1485 